\begin{tabular}{|l|l|}
\hline $\begin{array}{l}\text { ESCOLA DE COMUNICAÇÃO, } \\
\text { ARTES E DESIGN }\end{array}$ & $\begin{array}{l}\text { mídia, cultura e tecnologia } \\
\text { Revista FAMECOS, Porto Al gre, v. 27, p. 1-13, jan.-dez. } 2020 \\
\text { PUCRS } \\
\text { FAMECOS }\end{array}$ \\
\hline e-ISSN: 1980-3729 | ISSN-L: 1415-0549 \\
\hline https://dx.doi.org/10.15448/1980-3729.2020.1.35896
\end{tabular}

AUDIOVISUAL

\title{
Notas sobre o documentário contemporâneo
}

\author{
Notes on the contemporary documentary \\ Notas sobre el documental contemporáneo
}

\section{Laecio Ricardo de Aquino Rodrigues ${ }^{1}$ 0000-0003-4539-646X laecioricardo@gmail.com}

Recebido em: 4 out. 2019 . Aprovado em: 26 abr. 2020. Publicado em: 17 set. 2020.

\section{(c) (1)}

Artigo está licenciado sob forma de uma licença Creative Commons Atribuição 4.0 Internacional.
Resumo: Neste artigo, apresento um panorama da produção contemporânea do documentário, ressaltando a sua complexidade e destacando algumas das suas tendências mais instigantes, a exemplo da proliferação dos dispositivos, da emergência dos filmes em primeira pessoa, da consagração do ensaio e da retomada dos arquivos com fins de ressignificação. No entanto, apesar do esforço analítico, é preciso lembrar que uma das caracteristicas do documentário, na contemporaneidade, se refere à complexidade das práticas filmicas que, não raro, conjugam diferentes procedimentos numa única obra, o que nos impede de investir em classificações rigorosas. Portanto, o texto se apresenta, prioritariamente, como um mapeamento e exploração desse campo artístico em sua multiplicidade, mas sem propósitos conclusivos ou assertivos.

Palavras-chave: Ensaio filmico. Dispositivo. Filmes em primeira pessoa.

Abstract: In this article, I present an overview of the contemporary documentary, pointing its complexity and highlighting some of its most interesting tendencies, such as the proliferation of dispositifs, the emergence of the first-person film, the acclamation of the essay and the retaking of archives with reassignment proposals. However, despite the analytical effort, it must be remembered that one of the key features of contemporary documentary refers to the complexity of filmic practices that often combine different procedures in a single work, which demands of us not to invest in strict classifications. Therefore, the paper presents itself primarily as a mapping and an exploration of this artistic field in its multiplicity, but without conclusive or assertive purposes.

Keywords: Film-essay. Dispositive. First-person documentary.

Resumen: En este artículo, presento una visión general de la producción contemporánea del documental, destacando su complejidad y algunas de sus tendencias más emocionantes, como la proliferación de dispositivos, la aparición de películas en primera persona, la consagración del ensayo y la reanudación de los archivos con fines de resignificación. Sin embargo, a pesar del esfuerzo analítico, debe recordarse que una de las caracteristicas del documental actual se refiere a la complejidad de las prácticas filmicas que a menudo combinan diferentes procedimientos en una sola obra, lo que nos obliga a evitar clasificaciones rigurosas. Por lo tanto, el texto se presenta principalmente como un mapeo y exploración de este campo artístico en su multiplicidad, pero sin propósitos concluyentes o asertivos. Palabras claves: Film-ensayo. Dispositivo. Películas en primera persona.

\section{Introdução}

Antes de qualquer mergulho analítico, gostaria de partilhar dois esclarecimentos importantes. Ambos se referem à gênese deste artigo. Primeiramente: ele foi parcialmente motivado por um texto de Cláudia Mesquita, publicado há 10 anos em Novos Estudos, no qual a pesquisadora 
mensura as singularidades estilisticas e estéticas (com os seus resultados politicos) da produção documentária brasileira que despontava naquele início de milênio, indicando, pois, um contexto de evidente renovação. À ocasião, quatro títulos impulsionaram suas considerações. São eles: Santiago (2007), de João Salles; Acácio (2008), de Marilia Rocha; Pan-cinema permanente (2008), de Carlos Nader; e Vida (2008), de Paula Gaitán.

Para entender a novidade da qual esses filmes eram portadores, é preciso não esquecer que a tradição do documentário brasileiro, embora tenha deixado de "falar sobre o outro" para "falar com o outro" (em uma evidente valorização da entrevista), sempre se caracterizou por uma espécie de gestão/controle da enunciação pelo diretor, com exceções pontuais. A essa tendência, se aliaria uma militância em prol das reivindicações sociais consideradas urgentes e pela abordagem dos excluidos - dos grupos tradicionalmente invisibilizados. Escolhas que, não raro, poderiam implicar em condescendência e/ou numa vitimização ainda maior desses contingentes, não obstante as intenções iniciais da equipe (BERNARDET, 2003; TEIXEIRA, 2012). Feita esta ressalva, podemos recapitular aqui algumas das características identificadas por Mesquita (2010).

No quarteto mencionado, notamos um movimento de redução do enfoque, que se caracterizaria pela adoção de um recorte modesto e atento à singularidade dos sujeitos abordados, em detrimento de qualquer pretensão para contemplar as grandes questões e dilemas da nossa sociedade; e também de recusa em construir narrativas totalizantes, que invistam em generalizações permeadas por comentários com finalidade expositiva e por vezes conclusiva. Ou seja, os personagens não são considerados simples "amostra" a serviço de uma enunciação indiferente e supostamente ilustrada, o que dificultaria igualmente a construção de relações de causa-efeito, bem como as inclinações do documentário para promover sinteses e se converter em "voz do saber". Nestas obras, como sugere Mesquita (2010), verificamos ainda a transição do regime representativo para o performático; em outros termos, a imagem deixa de ser um abrigo para a construção de um registro formal e controlado, onde se encontram separados diretor e personagem, para se tornar um lugar de performance - de reinvenção cênica dos sujeitos, não raro atravessada por um desejo de exposição da intimidade. Assim, com o gradual apagamento das distâncias e protocolos entre quem filma e quem é filmado, a obra se converteria numa espécie de "dança a dois", composta de fragmentos e descontinuidades, em vez de uma narrativa linear com ambições de precisão. Na avaliação da pesquisadora, estas mudanças dialogariam com revisões operadas na prática etnográfica (dialogia e polifonia) e historiográfica (valorização da micro-história). E, ante a alegação crítica de que o afastamento dos "grandes temas" empobreceria o documentário, Mesquita acrescenta: a ênfase no micro não nos impede de tangenciar/alcançar o macro; afinal, as vidas individuais também são atravessadas pelos problemas mais gerais, bem como pelas grandes narrativas. Por fim, uma última observação sobre o quarteto filmico analisado: nessas obras, constatamos a intensificação de práticas reflexivas dirigidas ao espectador e que colocam em suspeição não apenas o filme em si, mas as próprias convenções do documentário. Assim, conclui Mesquita (2010), são títulos que produzem "uma imagem-reflexão e não uma imagem-reflexo"; que desconstroem, portanto, as expectativas tradicionais em torno do documentário.

Mas, ao investir nesta sintese, não desejo afirmar que tais características despontam como novidade nesses filmes - algo como se neles avistássemos uma ruptura drástica com as tendências anteriores. Verificamos antes um processo de transição e de gradual afirmação, e que encontra nessas obras uma etapa de consolidação. Por outro lado, cabe lembrar que a ascensão dessas práticas tampouco implica uma mudança radical do campo do documentário - uma espécie de apagamento das tendências outrora em voga. Ao contrário, é preciso lembrar que na seara artística o novo não raro convive com a tradição; e que os revivals, com frequência, promovem releituras que nos desautorizam de pensar em evolucionismos, teleologias. 
No entanto, se a motivação deste artigo tem sua inspiração parcial no estudo de Mesquita, a inclinação definitiva para redigi-lo despontou em 2019, após ministrar uma disciplina na Pós-Graduação voltada à produção documentária contemporânea. Concluida essa jornada frutífera com os estudantes, senti-me estimulado a partilhar essa experiência panorâmica num estudo sistematizado. O presente texto surge, pois, norteado por essa ambição, compondo uma espécie de "estado da arte"2, mas sem pretensões de promover esgotamentos.

\section{Tendências contemporâneas}

De partida, admito que o estudo panorâmico delineado neste artigo enfrenta uma dificuldade considerável, posto que uma das características mais notáveis do documentário, na contemporaneidade, se refere à complexidade das práticas filmicas que, não raro, conseguem conjugar diferentes procedimentos numa única obra, o que restringe qualquer esforço analítico e classificatório rigoroso. Assim, se opto aqui pela demarcação de algumas dessas tendências de modo apartado se trata tão somente de um recurso didático para facilitar o percurso do leitor; mas tenho ciência de que alguns dos títulos citados ${ }^{3}$ facilmente entrelaçam mais de uma vertente em sua urdidura.

Essa observação nos conduz à outra, igualmente relevante: se no contexto do documentário clássico e moderno (de 1920 a 1970), era relativamente seguro mobilizar um arsenal teórico para nos aproximarmos dos filmes com finalidade investigativa, deduzimos que, na contemporaneidade, esta "convocação às armas" é mais desafiadora. Ou seja, já não basta nos vincularmos a um ou outro autor somente, tampouco em nos fiarmos apenas à teoria do cinema; para estarmos à altura das provocações instigadas por essas obras, é preciso expandir o diálogo com outros campos artísticos e diferentes disciplinas, como a filosofia, a história da arte e a antropologia, dentre outras. Portanto, se trata agora de ampliar o referencial analítico para não mensurarmos os filmes "por baixo".

Uma última ressalva me parece importante: se o contexto a ser privilegiado neste estudo é o da contemporaneidade do documentário, cabe informar que as práticas que destacaremos não são, exatamente, modalidades recentes. Pelo menos em sua maior parte. Embora paradoxal, a observação não destoa de algo já mencionado: no campo artístico, a novidade não necessariamente está apartada da tradição; e são comuns as releituras que nos impedem de pensar em evolucionismos e rupturas definitivas. Assim, em parte das vertentes evocadas, testemunharemos uma retomada e intensificação de tendências anteriores, porém sob novas e instigantes premissas.

\section{A febre dos dispositivos}

Inicialmente, gostaria de revisitar o conceito de dispositivo vinculado à prática documentária e que, notadamente no caso brasileiro, se converteu em método abraçado por muitos realizadores contemporâneos, tanto no âmbito amador quanto profissional. Reformulado por Foucault (2000) para ilustrar as implicações do poder disciplinar sobre os individuos nas sociedades modernas, promovendo efeitos de assujeitamento ou instigando novas subjetividades, essa categoria tem se revelado fértil para um melhor entendimento do campo artístico aqui investigado. Sobretudo enquanto estratégia criativa capaz de produzir acontecimentos que recusam o domínio pleno do realizador e que acolhem o imprevisto em suas tomadas, promovendo assim uma reabilitação da imagem ante o "cinema" desgastado pelo artifício, pelo controle e roteirização excessiva (COMOLLI, 2008).

A partir da leitura de Vigiar e punir, entendemos que o dispositivo abriga um conjunto de forças heterogêneas (elementos arquitetônicos e técnicos, redes discursivas e afetivas, protocolos

\footnotetext{
2 Sobre este tipo de investigação, Norma Ferreira (2002) aponta: são estudos que visam mapear e discutir as tendências que, no âmbito acadêmico, têm se destacado num periodo, impulsionando a produção de dissertações, de teses e de dossiês em periódicos diversos, além de se converter na temática central de muitos congressos.

3 Neste artigo, não desejo investir em análises filmicas, salvo exceções pontuais e com fins de contextualização. Assim, interessa-me prioritariamente delinear algumas das tendências que proliferam na contemporaneidade do documentário, em sintonia com o que designei de "estado da arte".
} 
juridicos) que promovem agenciamentos no tecido social. Como observa Giorgio Agamben (2009), o dispositivo resultaria da convergência entre relações de poder e de saber (coerções e epistemes), instigando modos de ser e de agir. É precisamente esta noção mais ampla - convergência de vetores promovendo efeitos relacionais e subjetivos - que será retomada por certa prática documentária contemporânea.

Para Jean-Louis Comolli, o dispositivo despontaria como princípio criativo capaz de restituir ao documentário a sua força política e de devolver alguma crença à imagem. E os filmes assim norteados caracterizar-se-iam pela renúncia do cálculo demasiado em benefício da convocação do acaso4; nos deparamos, pois, com obras que se recusam a disciplinar o caos do mundo e que se abrem para aquilo que ameaça sua própria estabilidade (COMOLLI, 2008, p. 169-178). Deste modo, a ação deflagrada pelo dispositivo visa acionar o impensado dos corpos, arrefecer os estados de vigilância e tensionar a cena. Em outros termos: mediante certo planejamento, o diretor concebe dispositivos no intuito de desprogramar as relações num grupo social ou de provocar acontecimentos no mundo para filmá-los; trata-se de um gesto ativo que visa redistribuir territórios e propor niveis de interação, estimulando as subjetividades envolvidas a se reinventar nesse processo (RODRIGUES, 2015). Em oposição aos roteiros que demandam controle extremo, os dispositivos extraem da incerteza e, porvezes, da partilha enunciativa sua condição de renovação ${ }^{5}$.

Em ensaio onde avalia a consolidação desta partilha, sobretudo no documentário brasileiro, Ilana Feldman (2012) considera tais práticas como "instigantes estratégias de inclusão do olhar e da palavra do outro", seja por meio de imagens produzidas pelos próprios personagens, seja por meio de registros não endereçados ao filme, mas retomados pelo diretor. Em tais títulos, nos diz ela, testemunhamos um esforço de reformulação da enunciação tradicional, mediante uma espécie de "retirada estética" do realizador, que tende a privilegiar na cena as interações entre os personagens. Mas não se trata de uma retirada integral, como se o cineasta abdicasse completamente daquilo que concebeu na origem, posto que seu retorno na montagem sinaliza um exercício de reapropriação criativa. Afinal, montar também pressupõe identificar e problematizar, no encadeamento das imagens, tensões e afetos nem sempre evidentes para os individuos que participam de uma mesma configuração social.

Para Mariana Souto (2012), esta partilha enunciativa, não raro, pode ser entendida como o emprego de dispositivos de infiltração por parte do diretor; ou seja, de estratégias para a abordagem de determinado universo social, com um mínimo de impacto e de teor invasivo, e cuja dinâmica seria alterada com a presença do cineasta. 0 filme assim realizado resultaria numa espécie de "direto interno", marcado por um adensamento da intimidade, intimidade que não é desvinculada de hierarquias e da afirmação de algum poder, o que torna as relações registradas complexas - nestas obras, coerções e constrangimentos se mesclariam a declarações de afetos. Com maior ou menor êxito, são muitos os títulos nacionais que adotam tais premissas, parcial ou integralmente, a exemplo de $O$ prisioneiro da grade de ferro (2003), de Paulo Sacramento; Rua de mão dupla (2005), de Cao Guimarães; Pacific (2009) e Câmara escura (2012), de Marcelo Pedroso; Doméstica (2013), de Gabriel Mascaro; e Gente bonita (2016), de Leon Sampaio.

\footnotetext{
4 Como ressalta Cezar Migliorin (2008), esta noção de dispositivo é tributária dos esforços alavancados por alguns realizadores da tradição moderna, como Jean Rouch, cujas estratégias filmicas visavam suscitar condutas fabulativas na tomada. Mas, em sintonia com Comolli (2008), podemos afirmar que a conjuntura atual que estimula a retomada dos dispositivos é mais complexa; afinal, é outro o contexto de profusão da sociedade do espetáculo, bem como de familiaridade do indivíduo com as câmeras e o aparato midiático. Assim, parafraseando o livro de Comolli, como a inocência se encontra perdida e o espetáculo aliado a uma verve exibicionista (SIBILIA, 2008), deduzimos que o desafio dos documentaristas contemporâneos é maior do que o dos seus pares modernos.

5 Todavia, é importante ressaltar que o dispositivo não opera pautado unicamente neste fundamento (esforço de coletivização da enunciação), consagrado pelo gesto de entregar a câmera aos personagens para que esses filmem a si e o seu entorno. Não raro, as regras propostas e os vetores acionados pelo diretor criam desafios e instabilidades para sua própria equipe, resultando em obras que conciliam um misto de acaso e de parcial controle, com desfechos incertos (RODRIGUES, 2015). Pensemos nos exemplos de Acidente (2005), de Cao Guimarães; O fim e o princípio (2005), de Eduardo Coutinho; 33 (2002), de Kiko Goifman; e Salve o cinema (1995), de Mohsen Makhmalbaf, dentre outros.
} 
Creio ser possível também afirmar que o emprego de dispositivos, sobretudo no documentário brasileiro, despontaria como tentativa de renovação da entrevista e de redimensionamento dos encontros nas obras que trabalham com tomada direta ${ }^{6}$. Desse ponto de vista, tal expediente visaria estimular e promover embates fecundos no lugar do apaziguamento e da conformidade tradicionalmente vislumbrados no telejornalismo e nos documentários convencionais. Como entender essa observação? Em certa medida, como tudo que se institucionaliza, a entrevista perdeu força, se converteu em recurso desacreditado. Na virada dos anos de 1990/2000, não foram poucas as vozes que questionaram este emprego limitado. Para Bernardet (2003), por exemplo, a entrevista se convertera em mero cacoete e o aumento da produção documentária não teria sido acompanhado de inovações estilísticas capazes de revitalizar tal expediente.

Acredito que tais críticas trouxeram consequências evidentes, como o gradual abandono da entrevista, em sua modalidade tradicional, por gerações recentes de documentaristas e o estímulo à adoção de dispositivos como tentativa de reposicioná-la em outros parâmetros? Como destaca André Brasil (2013), frente a este "dialogismo domesticado" e diante da opacidade do outro filmado, o dispositivo proporcionaria a emergência de uma realidade filmica na qual os personagens podem desenvolver autonomamente as suas performances e, em certos casos, prescindindo do diretor em cena. De modo ilustrativo, indico alguns títulos nos quais testemunhamos esta renovação da entrevista, propiciada pelo emprego de dispositivos. São eles: Close up (1990), de Kiarostami; Salve o cinema (1995), de Makhmalbaf; Rua de mão dupla (2005), de Cao Guimarães; Jogo de cena (2007), de Coutinho;
Doméstica (2013), de Gabriel Mascaro; e o menos conhecido Sete Visitas (2015), de Douglas Duarte.

Detenhamo-nos nesse último. O filme de Duarte não recorre à partilha enunciativa (nele não há redistribuição de câmeras). Em cena, Silvana de Almeida, ex-boia-fria, e atualmente uma operária da indústria têxtil, recebe em estúdio a visita de sete convidados que, individualmente ou em duplas, têm a incumbência de entrevistá-la. Não há referências prévias sobre a personagem a ser perscrutada, de modo que os encontros ocorrem às escuras, com exceção da última sequência, quando Silvana é confrontada pela própria filha. Também não fica evidente se os convidados sabem que Silvana será abordada por outras visitas com diferentes perfis.

Em algumas entrevistas, notamos o estabelecimento de certa reciprocidade e a abordagem evolui para uma conversa; em outras, permanece uma avaliação unilateral, quase um diagnóstico, não obstante o esforço da personagem para se posicionar e se afirmar no embate. Por vezes, um mesmo fato é contado de forma detalhada ou resumida, em virtude do tipo de pergunta endereçada a Silvana e da maior ou menor disposição do entrevistador em cena. Disponibilidade que é proporcional à inclinação ou não da operária para aderir ao jogo. Assim, numa primeira leitura, Sete visitas pode ser entendido como um filme sobre as metamorfoses do entrevistado no decorrer de vários encontros: uma avaliação de sua desenvoltura e da astúcia desenvolvida (o que deseja entregar ou ocultar e como se posiciona a cada novo desafio).

Mas, decorridos os encontros, e uma vez familiarizado com o dispositivo da obra, talvez coubesse perguntar: afinal, nessas visitas, quem se revela mais? Que pólo da entrevista o diretor deseja, de fato, perscrutar? Tais questões antecipam minha segunda hipótese de leitura: no

\footnotetext{
6 O termo direto no cinema se refere aos títulos que optam pelo registro síncrono de som e imagem, conquista técnica alavancada nos anos de 1960, com o uso de bobinas de maior duração e o emprego de gravadores acoplados a câmeras de maior portabilidade. tecnologia impulsionada nas décadas seguintes com o vídeo e o digital.

7 Para aprofundamento, indico uma série que tenho publicado na revista Doc Online com o propósito de investigar a prática da entrevista no documentário contemporâneo, atenta às obras que, recorrendo a um ou outro expediente, conseguem oxigenar e inovar este recurso. Partilho assim os links dos primeiros textos já disponibilizados. São eles: "Do encontro previsivel à cena revigorada - a entrevista no documentário contemporâneo (parte 1)", disponivel em http://doc.ubi.pt/index19.html. Acesso em: 18 abr. 2020. "Do encontro previsivel à cena revigorada - a entrevista no documentário contemporâneo (parte 2)", disponivel em http://ojs.labcom-ifp.ubi.pt/index. php/doc/issue/view/17/showToc. Acesso em: 19 abr. 2020. "Do encontro previsivel à cena revigorada - a entrevista no documentário contemporâneo (parte 3)", disponivel em http://ojs.labcom-ifp.ubi.pt/index.php/doc/article/view/677. Acesso em: 19 abr. 2020.
} 
fundo, Sete visitas almejaria investigar a conduta e a disposição do entrevistador, sugerindo que nossas perguntas, antes de tudo, são reveladoras de nossa visão de mundo; e que a linguagem corporal adotada pode indicar disponibilidade ou esquiva formal. Em outros termos, em sua ambição final, visita após visita, o documentário se direcionaria ao pólo da entrevista que tradicionalmente porta dúvidas e se resguarda na formalidade de condutor da conversa.

\section{"Escritas de si" no documentário}

Em texto anterior, defendi que o documentário, em seu exercício prático, tende a nos reconciliar com o mundo, com o tecido e a diversidade da vida, ao mesmo tempo em que nos obriga a reconhecer certos etnocentrismos e a explicitar nossos lugares de fala (RODRIGUES, 2017). Paixão pela alteridade, redescoberta de si no outro e vice-versa, revisão de nossas convicções - eis uma definição possivel para essa atividade. embora não desprovida de limitações. Cinema em atrito com o mundo e não em conformação, aponta Comolli (2008). Dito de outra forma: infinitas possibilidades de tateio do real pelo diretor e sua equipe, tendo o aparato maquínico como instrumento de intervenção, de provocação.

Com raras exceções, portanto, não fazemos um documentário sozinho, tampouco apartado da urgência dos nossos dias - sem conexão com as alteridades que nos cercam e os dilemas de nosso tempo. Não se trata, pois, de obra autoreferenciada. Assim acreditávamos. Porém, desde o fim dos anos de 1970, como indicam Michael Renov (2004) e Laura Rascaroli (2009), desponta no campo do documentário uma vertente marcada pelo triunfo da enunciação em 1a pessoa, articulada majoritariamente pelo diretor, cuja presença fisica (voz e/ou corporalidade) se afirma na tomada. Nessa tendência, o documentarista não é mais um mediador, mas alguém que deixa o antecampo, ocupa a cena e partilha conosco algumas de suas inquietações pessoais, num transbordamento subjetivo surpreendente, não raro com tonalidades autobiográficas ${ }^{8}$.

Não obstante o aspecto sedutor desta vertente filmica de denominações ambíguas ${ }^{9}$ - afinal, sentimo-nos atraidos por esta presença cênica adensada, ora performática, ora confessional -, penso que grande parte dos títulos que integram essa modalidade se depara com um desafio incontornável. Podemos sintetizá-lo: de que modo, nessas obras, a autoreferencialidade (a primazia do eu) possibilita igualmente o envolvimento de diferentes trajetórias e a promoção de múltiplos engajamentos (sobretudo espectatoriais), sem culminar - o filme - numa obra ensimesmada? Ou seja, como conectar outras alteridades num discurso marcado pela explicitação do intimo? Como converter este relato de si também em uma narrativa de outros?

Para fins ilustrativos, aponto algumas obras inseridas nessa tendência, certamente uma das mais fecundas da contemporaneidade do documentário. São elas: E agora? Lembra-me (2013), de Joaquim Pinto; A imagem que falta (2013), de Rithy Panh; Elena (2012), de Petra Costa; Mataram meu irmão (2013), de Cristiano Burlan; Los rubios (2003), de Albertina Carri; O tempo e a cidade (2008), de Terence Davies; No interior da minha mãe (2014), de Lucas Sá; Mauro em Caiena (2012), de Leonardo Mouramateus; Seams (1993), de Karim Ainouz; Tarnation (2003), de Jonathan Caouette; Balaou (2007), de Gonçalo Tocha; e Last words (1998), de Johan van der Keuken, dentre muitas outras.

\footnotetext{
8 Das tendências apresentadas neste artigo, esta talvez seja a única que poderiamos reconhecer como contemporânea. Ou seja, cujo florescimento e maturação ocorreram nos últimos 30 ou 40 anos. Como esclarece Renov (2004), embora tenha se consolidado sob a égide de uma pretensa objetividade, manifestações subjetivas sempre despontaram no documentário, com maior ou menor intensidade ao longo de sua história. Assim, em graus diferentes, realizadores diversos conseguiram impor suas visões de mundo às obras por eles assinadas; uma subjetividade que se afirmava no enquadramento, na delimitação das fontes abordadas, nos comentários em voz over e no expediente da montagem, dentre outras variáveis que facultavam tal expressão. Porém, a novidade em voga na vertente aqui destacada é uma exposição mais enfática da subjetividade do cineasta via uma construção enunciativa amparada na $1^{a}$ pessoa (um falar de si com pendor confessional), muitas vezes também associada à sua presença física na tomada. Tal prática, portanto, me parece se afirmar na contemporaneidade. 9 Dentre as denominações que the são regularmente atribuídas, podemos destacar: documentário em 1a pessoa, documentário subjetivo, documentário autobiográfico, documentário performático e documentário e escritas de si, sendo este último termo o que me parece mais adequado, posto que menos pressionado pelas categorias vinculadas às demais designações. Apesar do uso indistinto, esta terminologia, como aponta Teixeira (2012), está longe de se converter em sinonimia, apresentando por vezes mais diferenças do que convergências entre si.
} 
De modo mais radical, alguns dos títulos vinculados a essa prática não apenas investiriam numa narrativa marcada pela exposição do íntimo, mas também optariam por uma espécie de concentração espacial cujo resultado se traduziria numa monotonia cênica das obras. Em outros termos, são filmes cuja locação prioritária é o que podemos designar, inicialmente, de espaços de intimidade (locações marcadas por certa memória afetiva e que, do ponto de vista narrativo, sugerem uma idéia de confinamento). Em maior ou menor grau, penso que os seguintes títulos se notabilizam pela concentração espacial: Diários (1973-1983), de David Perlov; Irène (2009), de Alain Cavalier; Isto não é um filme (2011), de Jafar Panahi; Os dias com ele (2012), de Maria Clara Escobar; Não é um filme caseiro (2015), de Chantal Akerman; e Gipsofila (2015), de Margarida Leitão. Se tal decisão tende a dificultar ainda mais o desafio anteriormente apontado, é surpreendente perceber como, em algumas dessas obras, seus diretores conseguem se esquivar do exercício confessional autocentrado e promover deslizamentos entre a memória individual e a memória social, entre a trajetória pessoal e a experiência coletiva, entre o privado e o público, entre a micronarrativa e a grande História ${ }^{10}$. Ou seja, constroem um movimento de saida, um fora, que afasta a obra do ensimesmamento radical.

Para finalizar este tópico, aponto uma última ressalva. Em muitos documentários dessa tradição, notamos que a inclinação autobiográfica tem impulsionado um esforço, por parte do diretor, para o estabelecimento de cronologias - como se os eventos passados pudessem ser recuperados numa narrativa estável, com balizas discerniveis. Para além do engodo evidente em tal decisão (ARTIĖRES, 1998; BOURDIEU, 2006), ela teria outra implicação problemática, que podemos traduzir como uma desconfiança ante a opacidade da imagem. Tentarei pormenorizar minha inquietação. Penso que, nesta prática documentária, os impasses relacionados à expressão subjetiva não podem ser apartados de uma reflexão sobre o potencial da imagem para evocar uma experiência, para construir um relato pessoal ou possibilitar a materialização de uma memória. De partida, devemos reconhecer a condição lacunar do registro imagético. Como nos alerta Didi-Huberman (2012), na imagem, o enquadramento pressupõe sempre alguma exclusão, condição que lhe impossibilitaria fixar todos os sentidos de um evento filmado ou fotografado; limitação que se revela incontornável se ponderarmos também a duração de um plano ou de um fotograma - afinal, o que podemos fixar no tempo exíguo de um disparo fotográfico? Tal restrição, todavia, não pode nos impedir de recorrermos ao arquivo imagético como evidência sensivel para ilustrar uma memória ou para estimular a imaginação histórica (mais à frente, voltarei a este tema). O problema consiste quando alguns cineastas, inconformados com essa lacunaridade constitutiva, insistem em produzir um "suprimento" imagético extra (planos adicionais) ou investem em relatos verbais para contornar o que eles julgam como déficit, como carência da tomada.

Assim, creio que nos títulos marcados pela primazia do eu, deveriamos igualmente mensurar se a lacunaridade da imagem é acolhida e trabalhada de modo criativo, levando o espectador a senti-la como uma opacidade inevitável (e a entendê-la como uma especificidade do suporte), ou se é encarada como um problema a ser driblado ante a pretensão de uma construção biográfica total e, claro, ilusória. Podemos ilustrar este dilema com o exemplo positivo de Rithy Panh, em A imagem que falta (2013). Como bem demonstrou o cineasta, essa ausência que alguns identificam como déficit precisa ser sentida e valorizada para melhor nos obrigar (a nós, espectadores) a um exercício do pensamento - a entender os vínculos possiveis entre cinema e história, imagem e testemunho. E no caso deste filme, que aborda a inexistência de registros sobre o genocidio ocorrido no Camboja nos anos de 1970, a melhor compreender o porquê desta falta (a entendê-la como parte

10 De um ponto de vista político, é importante ressaltar que esta prática documentária amparada na primeira pessoa também possibilitou a emergência de filmes que, debitários de uma espécie de militância do diretor (vínculos com a comunidade LGBT, com o movimento negro e o feminismo, por exemplo), terminam por se constituir em discursos afirmativos destas minorias e em contradiscursos (narrativas dissensuais e de resistência) frente às construções hegemônicas na sociedade, que, não raro, são parciais e tradicionalmente excludentes. 
do próprio esforço de apagamento perpetrado pelo Khmer Vermelho). Em sintese, Panh não pode, e não deve, nos fornecer um suprimento imagético porque precisamos sentir esta falta (a destruição ou inexistência dos registros) como parte da operação genocida que vitimou o seu povo. Tentar contornar essa lacuna implicaria, pois, em minimizar a contundência do extermínio.

\section{A consagração do ensaio e a retomada dos arquivos}

De partida, gostaria de introduzir uma observação. A abordagem ensaística não tardou a mobilizar entusiastas na seara cinematográfica, ainda que a prática, nesse caso, tenha antecedido um diagnóstico mais rigoroso e a identificação de um corpus filmico robusto - arqueologia só elaborada a partir dos anos de 1990. Esses diretores pioneiros possivelmente foram afetados pela acalorada defesa do ensaio por Adorno (2003) - uma forma discursiva metodicamente sem método, atenta à eloquência e à expressividade, e que visa à articulação de saberes sem viés conclusivo, desafiando assim polaridades já estabelecidas no campo acadêmico (razão e sensibilidade, essência e aparência, realidade e ficção). Ou pelas observações de Max Bense (2014), para quem o ensaio resulta de uma combinação do gênio aliado a uma extraordinária potência imaginativa, num tipo de experimento no qualé preciso incluir a si mesmo (seu autor precisa estar implicado no discurso). Ou ainda impulsionados pelo visionário texto de Alexandre Astruc (1999), para quem a arte cinematográfica, em processo de transição, estava a caminho de se converter num campo para a plena expressão do pensamento, em suas diferentes veredas e complexidades. Nenhum domínio das idéias, nos diz ele, lhe deve ser interdito (ao cinema); uma vocação tão evidente, a ponto de Astruc afirmar que um Descartes contemporâneo certamente haveria de preferir "escrever" o seu Discurso do método em filme.
Fato é que, em sintonia com a circulação destes textos ${ }^{11}$, nos anos de 1950, uma produção majoritariamente oriunda da França coloca o ensaio filmico na ordem do dia. Obras como As estátuas também morrem (1953), de Resnais e Marker; Cartas da Sibéria (1957), de Marker, cujo nome, doravante, se torna indissociável desta prática; Noite e Neblina (1955) e Toda a memória do mundo (1956), de Resnais, dentre outros títulos, demarcam o lugar do ensaismo no cinema ${ }^{12}$. A essa primeira leva, sucederam-se outras vagas nas décadas seguintes: Agnès Varda e Godard abraçam a novidade entre os anos de 1960 e 1970; Alexander Kluge e Johan Keuken, idem; Harun Farocki, Marlon Riggs e Trinh T. Minh-Ha, a partir de 1980; dezenas de cineastas a ela aderem após a virada do milênio. Um movimento também evidente no Brasil, onde nomes como Arthur Omar, Rogério Sganzerla, Andrea Tonacci, Carlos Nader, Cao Guimarães e Eryk Rocha, ainda que pertencentes a gerações distintas, têm parte do seu trabalho marcada pelo viés ensaístico.

Mas se o ensaio audiovisual se converte em modismo na contemporaneidade, a sua expansão nos traz desafios nada fáceis. O principal deles seria a imprecisão conceitual, o que promoveria uma elasticidade demasiada da categoria, aspecto nem sempre positivo, posto que dificulta o seu manejo, a torna fugidia e a converte em redoma fácil para o abrigo de obras que, embora desafiem o formato narrativo canônico, não seriam necessariamente ensaísticas (WEINRICHTER, 2007; TEIXEIRA, 2015). Assim, se não convém engessar o ensaio, atitude que estaria na contramão do gesto evocado por Adorno, cabe ressaltar que essa abertura excessiva também não é auspiciosa.

O impasse conceitual nos leva a outro problema: a dificuldade classificatória. Em outros termos, como posicionar o ensaio na decantada divisão da arte cinematográfica? Há quem o identifique como um quarto domínio, um território a fazer frente

\footnotetext{
11 Embora os três textos aqui mencionados (de Adorno, Bense e Astruc) tenham sido traduzidos para o português na virada do milênio cabe ressaltar que ambos foram escritos entre as décadas de 1940 e 1950.

12 Uma arqueologia mais abrangente precisaria retomar as contribuições da vanguarda (Hans Richter), dos cineastas soviéticos (Eisenstein e Vertov, sobretudo) e o pioneirismo de Georges Franju e de Humphrey Jennings, dentre outros. Mas reitero que não é minha proposta aqui recuperar a história do ensaísmo no cinema. Por outro lado, acredito que o ensaio filmico só desponta com ênfase a partir desta safra que emerge nos anos de 1950. Para uma revisão mais acurada remeto aos títulos de Corrigan (2015). Teixeira (2015) e Rascaroli (2017).
} 
à ficção, ao documentário e ao experimental, tríade consolidada nos anos de 1920 (TEIXEIRA, 2015); outros preferem situá-lo como uma prática fronteiriça, a entrelaçar característica dos campos anteriores, notadamente do documentário e do experimental (CORRIGAN, 2015). Entre nós (caso brasileiro), percebo que este debate, com sua vitalidade e desafios, se aninha no território do documentário, ampliando assim o escopo dos investigadores dessa tradição; talvez porque os estudiosos do cinema ficcional, em seus esforços para organizar a história desta arte como uma intercalação de escolas circunscritas à ficção narrativa, tenham demonstrado menor interesse pelas formas dissidentes, não hegemônicas.

Embates à parte, no cinema, como na sua modalidade escrita, a prática ensaística se diferencia do formato expositivo ou assertivo - se trata, pois, de uma construção discursiva sem rígidas amarras e que comporta margens de ambiguidade, facultando assim maior liberdade interpretativa ao espectador. Como sugere Adorno (2003), ela procede por certezas provisórias, alternando breves avanços com eventuais recuos ${ }^{13}$. E, se em muitos títulos, percebemos certa preocupação com a expressividade, cumpre destacar outra característica: a subjetividade do enfoque, posto que as inquietações do autor permeiam a abordagem. Atributo que fomentou uma revalorização da voz over na prática audiovisual; se, no documentário expositivo, ela era sinônimo de autoridade e de simplificação de sentidos, reduzindo a autonomia do público, ela agora retorna reconfigurada implicada, afetiva e afetada, oscilante e incerta, analítica e provocativa, mas não mais dogmática. Em muitos filmes ensaísticos, testemunhamos também uma explicitação da mediação (do aparato, do método empregado e do processo de montagem) e um questionamento da própria imagem documental (não raro, acionando dúvidas e a colocando sob suspeita), procedimentos que solicitam um papel mais ativo do espectador.

Algumas das vertentes aqui discutidas (as obras articuladas em primeira pessoa e os títulos amparados em dispositivos) podem dialogar e resultar em ensaios filmicos, reiterando o que poderiamos descrever como uma porosidade incontornável da contemporaneidade do documentário. Mas o vínculo maior do ensaio, a meu ver, se efetiva nas produções que investem na retomada de arquivos audiovisuais (de imagens e sons do passado) com propósitos de ressignificação - de mapear latências e novas camadas de sentidos nestes registros. O que não deixa de ocasionar duas confusões recorrentes: a) o entendimento de que todo ensaio audiovisual envolve sempre o emprego de arquivos, quando, na verdade, também dispomos de trabalhos ensaísticos construídos com tomadas originalmente endereçadas ao filme; b) a leitura de que o uso dos arquivos, no documentário, ocorreria sempre na criativa chave da ressignificação, quando na realidade são comuns os empregos que se aproximam do propósito ilustrativo evidente no telejornalismo (de apenas fazer referência a um evento passado).

De qualquer modo, aqui nos interessam os trabalhos onde este diálogo manifesta criatividade, sendo a obra final portadora dos atributos da abordagem ensaística já expostos. Mas, antes de novos avanços, duas outras observações me parecem pertinentes: a retomada dos arquivos, ressalto, não é prática exclusiva do documentário, embora seja neste campo que nos deparemos com os exemplos mais potentes. Além do cinema, certa produção televisiva e/ou voltada para internet, bem como muitas instalações em museus, se utilizam deste recurso, com maior ou menor eficácia. Por outro lado, mesmo no domínio do documentário, também não é uma prática recente, embora se converta numa forte tendência contemporânea.

Feito tais esclarecimentos, e partindo das premissas que aqui nos interessam, o que seria um filme de arquivo? São obras que insuflam e revigoram imagens/sons produzidos por outros e em tempos passados; registros esmaecidos, talvez esquecidos e confinados a permanecer

13 Em vez de indicar hipóteses e de articular uma investigação com finalidade conclusiva, o ensaio se apresenta mais como um esboço das possibilidades de abordagem e de entendimento de um tema, sem pretensões de promover sinteses ou fechamentos. Inconcluso e fragmentário, ele parece recusar qualquer sistematização excessiva. Por isso, se diz que o ensaio representa o indeterminado do pensamento - suas oscilações - no próprio ato de pensar (ADORNO, 2003). 
retidos nos arquivos públicos e privados, nas cinematecas e "bancos de imagem" das emissoras. Portanto, são produções que injetam vitalidade aos registros do pretérito, vislumbrando neles diferentes arranjos e camadas de sentidos (o trabalho de ressignificação), e assim promovendo novos entendimentos históricos. Para fins didáticos, e por ter maior afinidade com o debate, referir-me-ei, a partir de agora, apenas ao arquivo imagético ${ }^{14}$, embora esteja ciente da importância dos arquivos sonoros nesta prática.

Uma imagem, lembremos, é um campo de conflitos semânticos, passivel sempre de novas atualizações; ela não é um objeto cujos sentidos são controlados pelo seu produtor e que se cristalizam de forma definitiva (ela sofre acréscimos/ redução/oscilação de sentidos com o transcorrer do tempo, modificações que carecem de sedimentação para serem percebidas e de outros olhares que aceitem indagá-las novamente) ${ }^{15}$. Para descobrir estas latências não evidentes no contexto de sua produção ou primeira veiculação, é preciso questioná-las, interrogá-las, colocá-las em outros fluxos e enfrentar sua opacidade. Didi-Huberman (2015) sugere, pois, que apenas na montagem novos sentidos e conexões podem ser estabelecidos. Essa tarefa de remontagem, contudo, é inesgotável e não visa teleologias; em outros termos, pode-se sempre retomar uma imagem e redistribui-la em novos arranjos, vislumbrando assim outras camadas semânticas. Em um ensaio interessante, Bernardet (2004) utilizará a expressão "migração das imagens" para se referir a este jogo de deslocamento e ressignificação, para destacar o que existe de indeterminado numa imagem e as suas possibilidades de recombinações.

Em sintonia com Didi-Huberman, podemos deduzir que a prática da montagem, aqui, ganha um sentido amplo: não se resume mais a tarefa de criar sintagmas - de definir um percurso de leitura - em atendimento a um plano de filmagem prévio. Em síntese, ela ainda despontaria como a potência do encadeamento, mas se notabilizaria, de fato, como a potência do contato e do acúmulo, como a atividade intelectual capaz de fazer aflorar novas percepções e entendimentos em torno de uma imagem, sentidos estes que não estavam evidentes nos seus usos anteriores.

Mas, nesta tarefa de investigar novas legibilidades, o que podemos demandar de uma imagem? O que dela exigir? Como estar à altura do desafio que implica olhar uma imagem e acolher suas demandas? Se uma imagem é uma evidência visivel do passado, poderia ela igualmente testemunhar sobre os eventos e vidas nelas inscritas? Por que a imagem ainda incomoda e, não raro, é alvo de hostilidades ou recusas? Imprecisa, a imagem inspiraria desconfianças; despontaria como campo polissêmico insuportável para o pesquisador que busca alguma exatidão. Didi-Huberman, em Imagens apesar de tudo (2012), desconstruirá essa crítica que poderiamos designar de iconofóbica, solicitando não uma aclamação da imagem, mas a sua justa mensuração. Temer as imagens, nos diz ele, é sempre menos enriquecedor do que enfrentá-las na sua complexidade. Para esse autor, ou se exige demais das imagens (que elas

\footnotetext{
14 Neste sentido, talvez caiba aqui fazer breve distinção entre o que seria um arquivo que já circulou publicamente (um registro que, veiculado em cinema, na televisão ou via outra plataforma, se tornou conhecido de algum modo) e aquilo que na tradição norte-americana se designa de "found-footage", expressão que parece se referir a registros até então desconhecidos, normalmente produzidos em condições amadoras (muitas vezes no âmbito privado e/ou familiar) e que, uma vez encontrados por um diretor e submetidos a operações de remontagem, permite novas legibilidades históricas.

15 Sobre os múltiplos sentidos que se fixam numa imagem, Comolli (2010, p. 337) nos diz algo similar: "A gravação das visibilidades e das temporalidades pela máquina cinematográfica 'capta' ou revela relações, ligações que não havíamos necessariamente visto ou compreendido no momento da tomada. [...] A natureza da imagem cinematográfica supõe e acarreta a impressão de elementos do mundo que não havíamos notado ou, menos ainda, calculado: alguma coisa de um 'real' ainda ilegivel, em gestação, em devir, portador de uma leitura e de um sentido futuros. Algo da dimensão do latente revela-se então. É a potência do cinema que está em jogo aqui. Um certo estado do mundo, do movimento do mundo, é ao mesmo tempo suscitado e gravado pelo cinema". Creio haver nesta passagem uma proximidade também com aquilo que Walter Benjamin (2012; 2017), em alguns de seus ensaios, designava de condição de vidência da fotografia. Algo como se a imagem fosse portadora dos futuros possiveis, de demandas sonhadas. Em outros termos, ela não nos informaria o futuro que é (aquilo que se tornou o presente do qual somos contemporâneos); antes, ela parece portar as promessas e demandas não consolidadas de uma geração, os sonhos possivelmente soterrados pelas engrenagens da história. Por isso, Didi-Huberman (2015), retomando Benjamin, nos dirá: diante de uma imagem, estariamos diante da voragem do tempo, com seus atravessamentos (os anacronismos e sobrevivências que pressionam o nosso devir), mas também diante destas promessas não concretizadas e que solicitam a nossa acolhida - o nosso olhar e solidariedade.
} 
representem os eventos integralmente), ou se opta por desqualificá-las sob a acusação de simulacro redutor (por sempre implicar um déficit), condição que ainda hoje ilustraria a resistência ao seu emprego na investigação histórica. Em contrapartida, Didi-Huberman (2015) insistirá no caráter profético das imagens: elas seriam portadoras de latências que só gradualmente se explicitam para um observador paciente. E, para mapeá-las, é preciso questionar as imagens via exercicios de montagem, deslocá-las para novos contextos e arranjos, no intuito de perscrutar seus sentidos e temporalidades, mas ciente de que nelas os eventos jamais se apresentarão integralmente. Por isso, a prática da montagem deve ser conjugada com um trabalho de imaginação histórica.

Fragilidade e inexatidão, no entanto, não seriam atributos exclusivos da imagem; antes, seriam propriedades comuns aos arquivos do passado. Como aponta a historiadora Arlette Farge (2009), diante de um arquivo é necessário adotar alguns procedimentos: estar disponivel e aceitar ser surpreendido e/ou contrariado pelos vestigios encontrados; praticar o despojamento (ou desapego) ciente de que o excesso de evidências pode ser prejudicial; e, por fim, talvez a observação mais relevante, aceitar a lacunaridade de qualquer documento - ou seja, entender que $o$ arquivo é, antes de tudo, falta e nunca a recuperação integral do passado investigado.

Por isso mesmo, o cuidado no seu manuseio é essencial para que distorções e excessos sejam evitados. Em se tratando do arquivo imagético, esta cautela - o respeito à opacidade e o reconhecimento da lacunaridade - é fundamental. Como nos alerta Sylvie Lindeperg (2016), são comuns os riscos de manipulação indevida das imagens do passado, sobretudo em atendimento às demandas de visibilidade do espectador contemporâneo. Dentre as práticas censuráveis, ela menciona as tentativas de colorização, a inserção de sons inexistentes, o reenquadramento, a celeridade da montagem e a indistinção na retomada dos arquivos (situação na qual registros institucionais, privados e publicitários, por exemplo, são mesclados indevidamente). Procedimentos que anulariam as referencialidades do documento e que o despojariam da sua condição de artefato histórico, obrigando-o a supostamente revelar aquilo que, na verdade, ele não poderia comunicar - um desejo de suprir e contornar seus limites, como se, através da manipulação indevida, o evento pudesse se materializar na íntegra e em conformidade com as aspirações do espectador do presente.

Em resumo: o arquivo não deve ser acolhido como evidência transparente; antes, deve ser encarado na sua opacidade (naquilo que revela e que oculta), como um objeto gerado por um determinado poder e acompanhado de intencionalidades. Ele não deve ser sacralizado, nem recusado de antemão, mas problematizado e continuamente remontado. Em se tratando da imagem, a observação é igualmente válida: ela revelaria algo, ao mesmo tempo em que encobriria outras informações. Propriedade que Didi-Huberman (2015) astuciosamente designara de imagem-malicia.

Este manuseio responsável, interessado nas latências, mas sem praticar distorções, é a lição que alguns cineastas-arquivistas nos têm ensinado com regularidade. Ao demonstrar sensibilidade para revisitar os registros do passado, mediante um trabalho de remontagem escrupuloso, eles nos sugerem novos entendimentos históricos para os episódios pretéritos, mas também nos ajudam a compreender o presente que habitamos e o futuro que almejamos consolidar. Uma virtude evidente em títulos como Elegia a Alexandre (1993), Sem sol (1983) e O fundo do ar é vermelho (1977), de Chris Marker; Operários ao sair da fábrica (1995) e Respite (2007), de Harun Farocki; El perro negro (2005) e Miss universo 1929 (2006), de Péter Forgács; a série História(s) do cinema (1988-1998) e o curta $A$ origem do século XXI (2000), de Godard; Um dia na vida (2010) de Coutinho; No intenso agora (2017), de João Salles; Retratos de identificação (2014), de Anita Leandro; 48 (2009) e Natureza morta (2005), de Susana de Souza Dias; A toca do lobo (2015), de Catarina Mourão; e Já visto jamais visto (2014), de Andrea Tonacci, dentre muitos outros.

\section{À guisa de inconclusão}

Procurei neste estudo contemplar algumas das vertentes mais instigantes em voga no documentário contemporâneo. Um exercício desafiador, 
mas fadado às limitações do próprio formato (a extensão do artigo, por exemplo). Assim, não obstante tenha cotejado práticas relevantes - o emprego de dispositivos, a emergência dos relatos autobiográficos, o ensaísmo e a remontagem dos arquivos -, reconheço que meu esforço representa, antes, um ponto de partida nesse debate do que um porto seguro. Cabe agora aos interessados avançar nos filmes e bibliografia mencionados, e construir o seu próprio percurso. Por outro lado, admito que outras tendências não foram contempladas nesta revisão, a exemplo das obras que intensificam os entrelaçamentos entre a ficção e o documentário, suscitando indiscernibilidades e subtraindo as tradicionais referências do espectador, e o chamado making of, espécie de documentário de bastidor (leitura simplista, ressalto) e um gênero que desponta com as mídias digitais, quase sempre associado às estratégias de marketing. Numa revisão futura, quem sabe, estas práticas encontrarão uma posterior inclusão, juntamente com outras que haverão de despontar.

\section{Referências}

ADORNO, Theodor. O ensaio como forma. In: ADORNO, Theodor. Notas de literatura I. São Paulo: Editora 34, 2003.

AGAMBEN, Giorgio. O que é o contemporâneo? E outros ensaios. Chapecó: Argos, 2009.

ARTIĖRES, Philippe. Arquivar a própria vida. Revista Estudos Históricos, Rio de Janeiro, n. 21, 1998. Disponivel em: http://bibliotecadigital.fgv.br/ojs/index.php/reh/ article/view/2061. Acesso em: 15 set. 2019.

ASTRUC, Alexandre. Nascimento de uma nova vanguarda: A "câmera-stylo". In: OLIVEIRA, Luis Miguel (org.) Nouvelle vague. Catálogo da Cinemateca Portuguesa: Ciência gráfica, 1999

BERNARDET, Jean Claude. Cineastas e imagens do povo. São Paulo: Companhia das Letras, 2003.

BERNARDET, Jean Claude. A migração das imagens. In: Teixeira, Francisco Elinaldo. (org.) Documentário no Brasil:Tradição e transformação. São Paulo: Summus, 2004.

BENJAMIN, Walter. Magia e técnica, arte e política. 8. ed. São Paulo: Editora Brasiliense, 2012.

BENJAMIN, Walter. Baudelaire e a modernidade. Belo Horizonte: Autêntica editora, 2017.

BENSE, Max. O ensaio e sua prosa. Revista Serrote, [s. l.], n. 16, 2014. Disponivel em: https://www.revistaserrote.com.br/2014/04/o-ensaio-e-sua-prosa/. Acesso em: 14 set. 2019.
BOURDIEU, Pierre. A ilusão biográfica. In: FERREIRA, Marieta de Moraes; AMADO, Janaina (org.) Usos \& abusos da história oral. Rio de Janeiro: Editora da Fundação Getúlio Vargas, 1996.

BRASIL, André. Formas do antecampo: performatividade no documentário brasileiro contemporâneo. Revista Famecos, Porto Alegre, v. 20, n. 3, p. 578-602, set./dez. 2013. Disponivel em: http://revistaseletronicas.pucrs.br/ojs/index.php/revistafamecos/article/ viewArticle/14512. Acesso em: 5 set. 2019. https://doi. org/10.15448/1980-3729.2013.3.14512.

COMOLLI, Jean-Louis. Ver e poder - A inocência perdida: cinema, televisão, ficção, documentário. Belo Horizonte: Editora UFMG, 2008.

COMOLLI, Jean-Louis; LINDEPERG, Sylvie. Imagens de arquivos: imbricamento de olhares. Entrevista com Sylvie Lindeperg. Catálogo do forumdoc. Belo Horizonte: Filmes de Quintal/FAFICH-UFMG, 2010. https:// doi.org/10.14409/ccd.v1i4.3981.

CORRIGAN, Timothy. O filme-ensaio: desde Montaigne e depois de Marker. Campinas: Papirus, 2015.

DIDI-HUBERMAN, Georges. Imagens apesar de tudo Lisboa: KKYM, 2012.

DIDI-HUBERMAN, Georges. Diante do tempo. Belo Horizonte: EDUFMG, 2015.

FARGE, Arlette. O sabor do arquivo. São Paulo: Edusp, 2009

FELDMAN, Ilana. "Um filme de": dinâmicas de inclusão do olhar do outro na cena documental. Revista Devires, Belo Horizonte, v. 9. n. 1, p. 50-65, out. 2012. Disponivel em: http://www.fafich.ufmg.br/ devires/ vgn1/download/03-ilana.pdf. Acesso em: 16 ago. 2019.

FERREIRA, Norma Sandra de Almeida. As pesquisas denominadas "estados da arte". Educação \& Sociedade, [s. l.], ano XXIII, n. 79, p. 257-272, 2002. Disponivel em: http://www.scielo.br/pdf/es/v23n79/10857.pdf. Acesso em: 30 jul. 2019. https://doi.org/10.1590/S010173302002000300013 .

FOUCAULT, Michel. Vigiar e punir. 26. ed. Petrópolis: Vozes, 2000.

LINDEPERG, Sylvie. O destino singular das imagens de arquivo. Revista Devires, Belo Horizonte, v. 12, n. 1, p. 12-27, ago. 2015. Disponivel em: http://www.fafich. ufmg.br/devires/index.php/Devires/article/view/342. Acesso em: 12 jun. 2019.

MESQUITA, Cláudia. Retratos em diálogo: notas sobre o documentário brasileiro recente. Novos Estudos, São Paulo, 86. ed., v. 29, n. 1, p. 104-118, mar. 2010. Disponivel em http://www.scielo.br/scielo.php?script=sci_arttext\&pid=S0101-33002010000100006. Acesso em: 12 ago. 2019. https://doi.org/10.1590/ S0101-33002010000100006.

MIGLIORIN, Cezar. Eu sou aquele que está de saída: dispositivo, experiência e biopolítica no documentário contemporâneo. 2008. 292 f. Tese (Doutorado em Comunicação e Cultura) - Escola de Comunicação, Universidade Federal do Rio de Janeiro, 2008. 
RASCAROLI, Laura. How the essay film thinks Nova York: Oxford University Press, 2017. https://doi. org/10.1093/acprof:0so/9780190238247.001.0001.

RASCAROLI, Laura. The personal camera: subjective cinema and the essay film. Nova York: Wallfower Press, 2009.

RENOV, Michael. The subject of documentary. Minneapolis: University of Minnesota Press, 2004.

RODRIGUES, Laécio Ricardo de Aquino. Notas sobre o dispositivo no documentário contemporâneo. Galáxia. São Paulo, n. 30, p. 138-148, dez. 2015. Disponivel em: http://revistas.pucsp.br/index.php/galaxia/article/ view/20160. Acesso em: 18 maio 2019

RODRIGUES, Laécio Ricardo de Aquino. Uma vocação chamada documentário. In: RICARDO, Laécio; FERRAZ, Txai; VIDAL, Thais (org.). Cinema e universidade: diferentes convergências. Recife: EDUFPE, 2017. Disponivel em: http://www.movfestival.com/2017/pt/ebook/. https://doi.org/10.1590/1982-25542015220160.

SIBILIA, Paula. O show do eu: a intimidade como espetáculo. Rio de Janeiro: Nova Fronteira, 2008.

SOUTO, Mariana. O direto interno, o dispositivo de infiltração e a mise-en-scène do amador - notas sobre Pacific e Doméstica. Revista Devires, Belo Horizonte, v. 9, n. 1, p. 66-85, 2012. Disponivel em: http://www. fafich.ufmg.br/ devires/vgn1/download/O4-mariana. pdf. Acesso em: 18 maio 2019.

TEIXEIRA, Francisco Elinaldo (org.). O ensaio no cinema. São Paulo: Hucitec, 2015

TEIXEIRA, Francisco Elinaldo. Cinemas não narrativos: experimental e documentário - passagens. São Paulo: Alameda, 2012.

WEINRICHTER, Antonio (org.). La forma que piensa. Tentativas en torno al cine-ensayo. Fondo de Publicaciones del Gobierno de Navarra, 2007. Disponivel em: http://mpison.webs.upv.es/ensayo_audiovisual/archivos/la_forma_que_piensa.pdf. Acesso em: 7 nov. 2018.

\section{Laécio Ricardo de Aquino Rodrigues}

Doutor em Multimeios pela Universidade Estadual de Campinas (Unicamp), em Campinas, SP, Brasil; professor do Departamento de Comunicação Social da Universidade Federal de Pernambuco (UFPE), em Recife, PE, Brasil.

\section{Endereço para correspondência}

Laécio Ricardo de Aquino Rodrigues

Universidade Federal de Pernambuco, Centro de Artes e Comunicação

Avenida Acadêmico Hélio Ramos, s/n

Cidade Universitária, 50670-900

Recife, PE, Brasil 